\title{
Novel fluorescent silver nanoparticles: sensitive and selective turn off sensor for cadmium ions
}

\author{
Bharat A. Makwana ${ }^{1} \cdot$ Disha J. Vyas ${ }^{1} \cdot$ Keyur D. Bhatt $^{1} \cdot$ Savan Darji $^{1}$ • \\ Vinod K. Jain ${ }^{1}$
}

Received: 3 April 2015/Accepted: 11 May 2015/Published online: 31 May 2015

(c) The Author(s) 2015. This article is published with open access at Springerlink.com

\begin{abstract}
The synthesis of metal nanoparticles by ecofriendly and reliable processes is an important aspect in many fields. In this study, octamethoxy resorcin [4] arene tetrahydrazide (OMRTH)-reduced and stabilized silver nanoparticles were synthesized via a simple one-pot method. Synthesized silver nanoparticles were characterized by UV-visible spectroscopy, transmission electron microscopy (TEM) and particle size analyzer (PSA). Furthermore, the application of OMRTH-AgNps as a simple, cost-effective and sensitive fluorescent sensor for rapid detection of cadmium was explored. Under optimum conditions, the fluorescence intensity of OMRTH-AgNps was inversely proportional to the cadmium concentration. Using OMRTH-AgNps as a selective and sensitive fluorescent probe, cadmium can be detected at a minimum concentration level of $10^{-8} \mathrm{M}$ in a facile way of fluorescence quenching, i.e., by a "turn off" mechanism. The method has been successfully applied for determination of $\mathrm{Cd}[\mathrm{II}]$ ions in groundwater and industrial effluent wastewater samples.
\end{abstract}

Keywords Calix[4]resorcinarene - Fluorescent . Quenching $\cdot$ Silver $\cdot$ Cadmium

Electronic supplementary material The online version of this article (doi:10.1007/s13204-015-0459-x) contains supplementary material, which is available to authorized users.

Bharat A. Makwana

bhrtchem1@gmail.com; dr.b.a.makwana@hotmail.com

1 Department of Chemistry, School of Sciences, Gujarat University, Ahmedabad 380009, India

\section{Introduction}

Nanoparticles have emerged as one of the most exciting areas of scientific endeavor in the last few decades in which chemical research plays a dominant role. Metal nanoparticles are of current interest because of a variety of potential applications ranging from chemistry to biological sciences. In most of their applications, the quality, size and the structure of nanoparticles will undoubtedly play a pivotal role in determination of their functions. As a consequence of reducing the size of noble metals, metal nanoparticles exhibit a variety of interesting properties such as catalytic, optical, electrical, magnetic and chemical, which are often different from their bulk counterparts (El-Sayed 2004; Hodes 2007; Murphy et al. 2008; Park et al. 2007; Xu and Suslick 2010). As noble metals are reduced in size to tens of nanometers, a new very strong absorption is observed resulting from the collective oscillation of the electrons in the conduction band from one surface of the particle to the other. This oscillation has a frequency that absorbs the visible light which is called the surface plasmon absorption (Burda et al. 2005). All these properties have caused the metal nanoparticles to play an important role in many areas. To utilize and optimize the properties of metal nanoparticles, a large spectrum of research has focused on the control of the size and shape, which is crucial in tuning their physical, chemical and optical properties (Klingelhöfer et al. 1997; Kim et al. 2004; Rahim et al. 2001; Raveendran et al. 2003). In this respect, size- and shape-selective synthesis of metal nanoparticles and their assemblies are of profound interest (Chen 2001; Puntes et al. 2002; Sau and Murphy 2004; Thomas et al. 2004). There are many synthetic methods for the synthesis of metal nanoparticles, such as electrochemical (Reetz and Helbig 1994), photochemical 
(Henglein 1993), sonochemical (Caruso et al. 2000; Fujimoto et al. 2001) and chemical reduction of the corresponding metal salts (Chung and Rhee 2004; Macdonald and Smith 1996). The most common synthetic technique for the fabrication of nanoparticles involved reduction of metal salts using reductants such as borohydrate (Bönnemann et al. 1994), citrate (Turkevich and Kim 1970), etc., in the presence of the protecting agent, which prevents the nanoparticles from aggregation and allows isolation of nanoparticles. There are many stabilizers listed in the literature.

Calix[4]resorcinarenes have received much attention in the recent past for their use as reducing as well as stabilizing agent for the preparation of nanoparticles (Alexander Wei et al. 2001; Balasubramanian et al. 2002; Ben-Ishay and Gedanken 2007; Kim et al. 2001, 2005; Kevin et al. 1999; Makwana et al. 2015; Misra et al. 2006; Yao et al. 2010) through cooperative, multidentate interactions (Kevin et al. 1999). Calix[4]resorcinarenes are three-dimensional cyclic aromatic tetramers and have an important advantage over calix[n]arenes, as they are readily obtainable with various substituents.

Most of the methods used for the formation of $\mathrm{Ag}$ nanoparticles from calix[4]resorcinarene limit their potential application, because they are prepared in organic solvents. However, which limits their potential applications, because of their poor solubility in aqueous media (Salorinne et al. 2011; Wei et al. 2001), which results in a poor shelf life (Balasubramanian et al. 2002, 2001; Stavens et al. 1999) Resorcinarene-functionalized metal nanoparticles such as AuNPs, AgNPs, PtNPs and PdNPs dispersed in aqueous medium are expected to have better biocompatibility and more promising applications than nanoparticles dispersed in organic phases (Makwana et al. 2014; Sun et al. 2010).

In recent years, there has been a growing need for developing highly sensitive and selective sensors for the detection of trace heavy metal ions from biological and environmental samples. The toxicity depends on the physical state, chemical form as well as the oxidation state.

Cadmium is widely used in a variety of industrial processes including batteries, alloys and coloring matters as well as electroplating products. Cadmium is also frequently found in fertilizer production using phosphate minerals and sewage sludge. The wide use of this element, unfortunately, has detrimental effects on human health as well as the environment. Cadmium can accumulate in organs, such as kidney, thyroid gland and spleen, which can induce physiological disorders, including renal dysfunction, calcium metabolism disorders and an increased incidence of certain cancers (Dobson 1992; Luo et al. 2007).

Many methods have been applied for the detection of toxic metal ions, among which fluorometry has gained much attention, because of its low cost, selectivity, sensitivity and response time. The design and synthesis of a sensitively and selectively fluorescent sensor is a most versatile and widespread approach for chemists (Curiel et al. 2005; Mizukami et al. 2002). The design and synthesis of fluorescent chemosensors are mainly based on fluorescent enhancement and fluorescent quenching modes, which are obtained by employing photoinduced energy transfer, photoinduced electron transfer, enhanced spinorbit and excited-state intramolecular proton transfer, etc. (Klein et al. 2001).

In that respect, recently researchers have developed fewatom, molecular-scale noble metal nanoclusters as a new class of fluorescence sensors (Zheng et al. 2007).These fluorescent metal nanoparticles have received considerable attention in the past few years owing to their great promise in a wide range of applications in bioimaging ( $\mathrm{Yu}$ et al. 2007), single-molecule studies and optical sensing (Triulzi et al. 2006; Huang et al. 2007, 2008) \{Kamali, 2015 \#3777\}\{Geng, 2014 \#3778\}\{Bao, 2014 \#3779\}\{Geng, $2014 \# 3780\}\{$ Sivaraman, 2014 \#3781\}\{Tharmaraj, 2011 \#3782 \} \{Sivaraman, 2014 \#3783\} \{Sivaraman, 2013 \#3784\}\{Sivaraman, 2012 \#3785\}. Among the many reported fluorescent chemosensors with fluorescence enhancement and quenching for metal ions, only a few cases have been explored for Cd [II] (Kim et al. 2012; Luo et al. 2007; Resendiz et al. 2004; Wang et al. 2013; Yin et al. 2011; Zhang et al. 2012).

Hence, there is a need for a rapid, reliable and highly sensitive sensor for cadmium detection (Velanki et al. 2007).Recent advancements have led to the deft preparation of highly fluorescent metal nanoclusters within biocompatible scaffolds (Bao et al. 2007; Ritchie et al. 2007; Shen et al. 2007; Zheng and Dickson 2002). For example, Dong and co-workers reported the water-soluble, fluorescent Ag nanoclusters using a common polyelectrolyte, poly (methacrylic acid) (PMAA) as the template upon photoreduction (Shang and Dong 2008). Dickson and coworkers have synthesized water-soluble fluorescent $\mathrm{Ag}$ nanoclusters using poly-(amidoamine) (PAMAM) dendrimer and DNA as templates (Petty et al. 2004; Zheng and Dickson 2002).

Here in this study, we report a simplistic and direct synthesis of fluorescent Ag nanoclusters using octamethoxy resorcin [4] arene tetrahydrazide (OMRTH) as a reducing as well as stabilizing agent. To the best of our knowledge, OMRTH was synthesized for the first time and used as both reducing and capping agent for the synthesis of fluorescent silver nanoparticles. This is a very convenient approach to make stable silver nanoparticles which was found to respond selectively and sensitively to $\mathrm{Cd}[\mathrm{II}]$ by means of fluorescence quenching. Therefore, they are expected to be promising fluorescent probes in many fields 
for the detection of cadmium. OMRTH-AgNps have also been used successfully for the determination of $\mathrm{Cd}[\mathrm{II}]$ ions in groundwater and industrial effluent water samples.

\section{Materials and methods}

\section{Materials}

All metal salts including silver nitrate $\left(\mathrm{AgNO}_{3}\right)$ were purchased from Sigma-Aldrich. Other reagents and solvents of analytical grade were purchased from commercial sources and used without further purification. All aqueous solutions were prepared from Millipore water (resistivity, $18 \Omega \mathrm{X}$; Millipore Systems). Fluorescence active TLC plates (F-2009) were obtained from Merck. The melting points (uncorrected) were obtained from a VEEGO (Model; VMPDS) melting point apparatus. Elemental analysis was carried out in vario MICRO_Variant elemental. FT-IR spectra were recorded on Bruker, tensor 27 Infrared spectrometer with samples prepared as $\mathrm{KBr}$ pellets. ${ }^{1} \mathrm{H}-\mathrm{NMR}$ spectra were recorded on an FT-NMR model Bruker, Avance II $(500 \mathrm{MHz})$ at $298 \mathrm{~K}$ with TMS as the internal reference. Mass spectra were recorded on JEOL SX 102/DA 6000 mass spectrometer using xenon/argon $(6 \mathrm{kV}, 10 \mathrm{~mA})$ as the FAB gas and ESI-MS was recorded on micromassQuarter2 mass spectrometer. Absorption spectra were studied on a Jasco V-570 UV-visible recording spectrophotometer. $\mathrm{pH}$ of the solutions was measured using pH analyzer LI 614Elico. The Malvern Zetasizer (Model ZEN3600) was used to estimate the particle size (e.g., hydrodynamic diameter) and for the zeta potential measurements by laser Doppler electrophoresis as such without dilution. TEM images were recorded in MACK/model JEOL, JEM 2100 at an accelerated voltage of $200 \mathrm{kV}$. A drop of dilute solution of a sample in water on carbon-coated copper grids was dried in vacuum and directly observed in the TEM. (Centrifuge) Fluorescence spectra were recorded on Jasco FP-6500 spectrofluorometer.

\section{Synthesis and characterization of compounds}

\section{Synthesis of compound 1}

Aqueous $\mathrm{HCl}(9 \mathrm{M}, 8 \mathrm{~mL})$ was added dropwise to a stirred solution of 1,3-dimethoxybenzene $(5 \mathrm{~mL}, 3.82 \mathrm{~mol})$ and 4-hydroxybenzaldehyde $(4.6 \mathrm{~g}, 3.82 \mathrm{~mol})$ in ethanol $(\mathrm{EtOH}, 62.5 \mathrm{~mL})$. The mixture was then stirred with reflux for 16 to $72 \mathrm{~h}$. The mixture was allowed to cool to room temperature and then filtered to yield the crude mixture of isomers as a purple powder, which was washed with cold methanol and further recrystallized in DMF-methanol mixture.
${ }^{1} \mathrm{H}$ NMR (500 MHz, DMSO-d6) d 8.79 (s, 4H, OH), 6.60 (s, 2H, ArH), 6.46 (s, 2H, ArH), 6.36 (m, 16H, ArH), $6.17(\mathrm{~s}, 2 \mathrm{H}, \mathrm{ArH}), 5.97$ (s, 2H, ArH), 5.49 (s, 4H, ArCH), $3.64(\mathrm{~s}, 12 \mathrm{H}, \mathrm{OCH} 3), 3.59(\mathrm{~s}, 12 \mathrm{H}, \mathrm{OCH} 3) ; v_{\max } / \mathrm{cm}^{-1}$ $3144,1611,1511,1465,1437,836,751 \mathrm{~cm}^{-1} ; \mathrm{mp} 320^{\circ} \mathrm{C}$ (decomp.); $\mathrm{m} / \mathrm{z}$ (relative intensity) $968.4[(\mathrm{M}-\mathrm{H}), 970(\mathrm{M}$ $+\mathrm{H}), 987\left(\mathrm{M}+\mathrm{H}_{2} \mathrm{O}\right), 992(\mathrm{M}+\mathrm{Na}),, 1008.3(\mathrm{M}+\mathrm{K})$. Anal.data for $\mathrm{C}_{60} \mathrm{H}_{56} \mathrm{O}_{12}$ (Found; C, 75.35; H, 6.05; O, 18.54 Calc.;C, 74.36; H, 5.82; O, 19.81) (Scheme 1; Moore et al. 2008).

\section{Synthesis of compound 2}

Octa-O-alkyl resorcin[4]arene(1) (4 g, $4.1 \mathrm{~mol})$, anhydrous potassium carbonate $(4.5 \mathrm{~g}, 4.7 \mathrm{mmol})$ and potassium iodide $(0.68 \mathrm{~g}, 4.0 \mathrm{mmol})$ in dry acetone $(150 \mathrm{~mL})$ were heated to reflux under nitrogen for at least $1 \mathrm{~h}$. Then ethyl bromoacetate $(5.51 \mathrm{~mL}, 4.7 \mathrm{mmol})$ was added and the reaction mixture was further refluxed for 7 days. After removal of acetone, the residue was dissolved in water, acidified with $\mathrm{HCl}$ and extracted with $\mathrm{CHCl}_{3}$. The yellow organic layer was separated and dried with $\mathrm{MgSO}_{4}$ and red oil, yielded after evaporation of the solvent, treated with alcohol to give a yellow product and further recrystallized from $\mathrm{EtOH}$ to give a pure yellow solid compound.

White solid, $51.7 \%$; mp $165^{\circ} \mathrm{C}$; IR (KBr) $v_{\max } / \mathrm{cm}^{-1}$ $1755(\mathrm{C}=\mathrm{O}) ;{ }^{1} \mathrm{H}$ NMR $(500 \mathrm{MHz}, \mathrm{DMSO}) \delta 6.6(\mathrm{~d}, 16 \mathrm{H}$, ArH), 6.2-6.3(s, 4H, ArH), 6.15(s, 4H, ArH), 5.64(s, 4H, $\left.\mathrm{Ar}_{3} \mathrm{CH}\right), 4.4-4.6\left(\mathrm{~m}, 8 \mathrm{H}, \mathrm{OCH}_{2}\right), 3.4-3.6\left(\mathrm{~m}, 24 \mathrm{H}, \mathrm{OCH}_{3}\right)$, 1.0-1.4 (m, $\left.20 \mathrm{H}, \mathrm{C}_{2} \mathrm{H}_{5}\right) ; \mathrm{m} / \mathrm{z} 1313.4$ Analytical data for $\mathrm{C}_{76} \mathrm{H}_{80} \mathrm{O}_{20}$ (Found; $\mathrm{C}, 70.12 ; \mathrm{H}, 6.05 ; \mathrm{O}, 25.73$ Calc.;C, 69.50; H, 6.14; O, 24.36).

\section{Synthesis of compound 3}

A mixture of compound $2(4.0 \mathrm{~g}, 2 \mathrm{mmol})$ and hydrazine hydrate $(20 \mathrm{~mL}, 80 \%)$ in $15 \mathrm{~mL}$ of EtOH was refluxed for $24 \mathrm{~h}$ and then allowed to cool at room temperature. A white-colored solid precipitated out and was washed with water to get the pure compound.

White solid, $85.0 \%$; $\mathrm{mp}>300{ }^{\circ} \mathrm{C}$; IR $(\mathrm{KBr}) v_{\max } / \mathrm{cm}^{-1}$ $3261(-\mathrm{NH}), 1503(-\mathrm{CONH}) \mathrm{cm}^{-1} ; \mathrm{m} / \mathrm{z} 1271.3$ Analytical data for $\mathrm{C}_{69} \mathrm{H}_{74} \mathrm{~N}_{8} \mathrm{O}_{16}$ (Found; $\mathrm{C}, 64.32 ; \mathrm{H}$ 5.95; N, 8.27; O, 20.95 Calc.; C, 65.18; H, 5.87; N, 8.81; O, 20.14).

\section{Synthesis and characterization of octamethoxy resorcin[4] arene tetrahydrazide (OMRTH)- protected silver nanoparticles (OMRTH-AgNps)}

In a typical experiments, synthesis of silver nanoparticles, take $5 \mathrm{ml}$ of $1.0 \mathrm{M}$ solution of octamethoxy resorcin (Park et al. 2007) arene tetrahydrazide (OMRTH) (3) was rapidly added to the $25 \mathrm{~mL}$ of $1 \mathrm{mM}$ boiling solution $\mathrm{AgNO}_{3}$ and 
<smiles>COc1cccc(OC)c1</smiles><smiles>O=Cc1ccc(O)cc1</smiles>

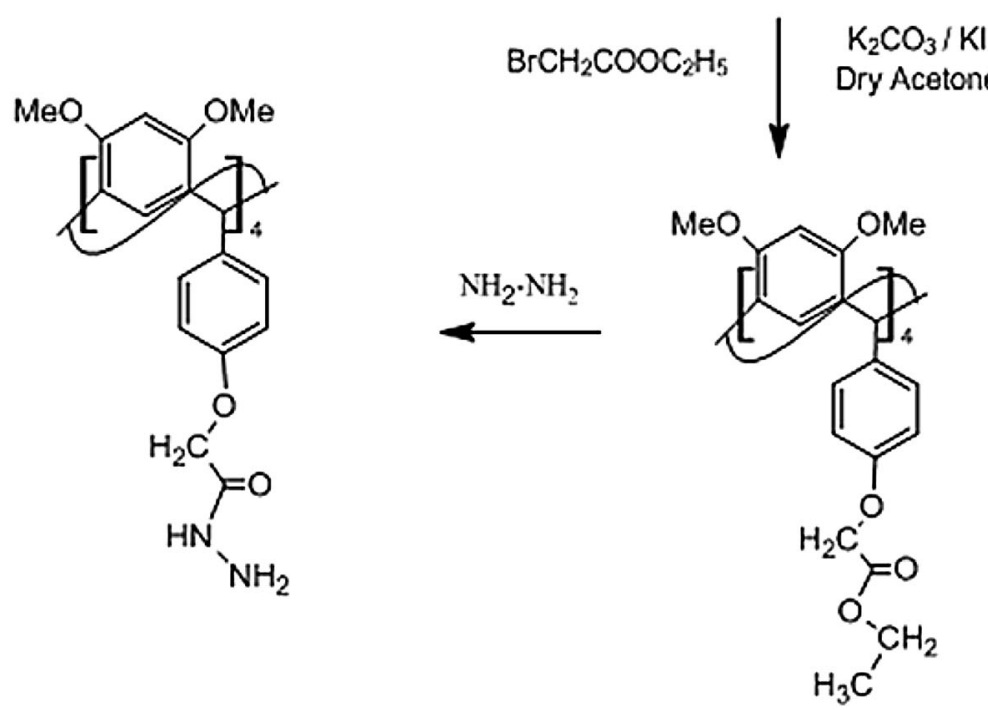<smiles>COc1cc(OC)cc(C2C3CCC2C2(CCCC2)C3)c1</smiles>

Scheme 1 Synthetic route of octamethoxy resorcin[4]arene tetrahydrazide<smiles>COc1ccc(C2=CC=CC2c2ccc(OCC(=O)NN)cc2)c(OC)c1</smiles>

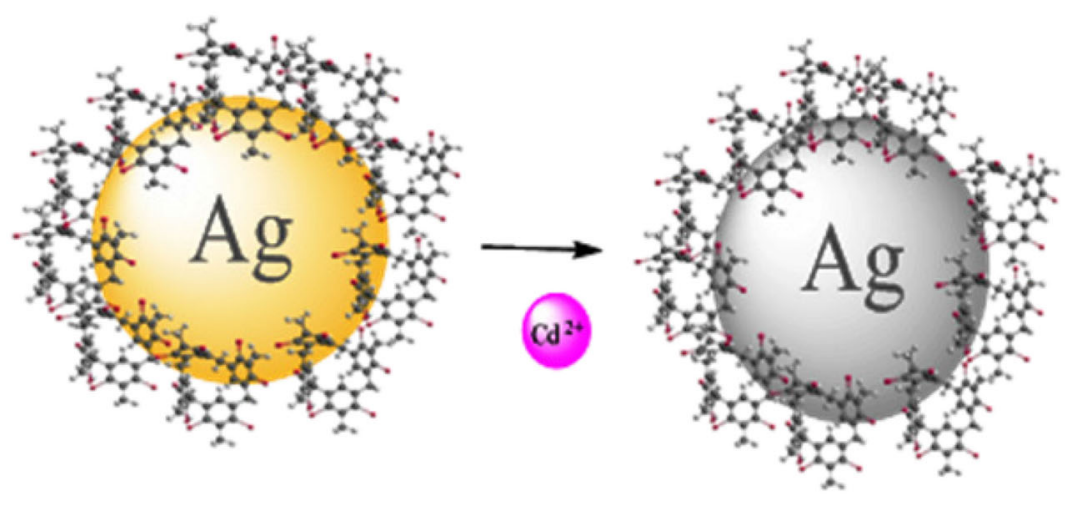

OMRTH-AgNps

\section{Fluorescent}

Scheme 2 Schematic representation showing the formation of functionalized silver nanoparticles $(\mathrm{AgNps})$ obtained by the reduction of $\mathrm{Ag} \mathrm{NO}_{3}$ with octamethoxy resorcin[4]arene tetrahydrazide

the heating was continued for $0.5 \mathrm{~h}$ and sitter further at room temperature for about $2 \mathrm{~h}$. The color of the solution changed from colorless to yellow, indicating the successful formation of silver nanoparticles. The resulting nanoparticle solution was centrifuged at $5000 \mathrm{rpm}$ for 5-7 min. This process was repeated three times to wash off the remaining residues and again dissolved in methanol for further studies. The residue was washed with copious amount of deionized water to remove any unbound molecules and again redispersed in deionized water to get $0.0053 \%$ solution of OMRTH-AgNps for further studies (Bhatt et al. 2014; Scheme 2). 
pH-dependent stability study of OMRTH-AgNps by UV-visible and fluorescence spectroscopy measurements

It has been found that $\mathrm{pH}$ has great effect on the stability of nanoparticles. Therefore, we determined the stability of OMRTH-AgNps at different $\mathrm{pH}$ values by measuring SPR and fluorescence. The $\mathrm{pH}$ of OMRTH-AgNps dispersion was adjusted using $0.1 \mathrm{M}$ hydrochloric acid and $0.1 \mathrm{M}$ sodium hydroxide solution ( $\mathrm{pH} \mathrm{4,} \mathrm{5,} \mathrm{6,} \mathrm{7,} \mathrm{8,} 9$ and 10) using a calibrated $\mathrm{pH}$ meter. Also, the change in SPR of the OMRTH-AgNps was recorded up to 60 days using UVvisible spectroscopy.

\section{Study of cation interaction with OMRTH-AgNps by absorption and emission spectroscopy measurements}

A $1 \mathrm{~mL}(1 \mathrm{mM})$ aqueous solution of $\mathrm{Zn}^{2+}, \mathrm{Pb}^{2+}, \mathrm{Co}^{2+}$, $\mathrm{Cu}^{2+}, \mathrm{Ba}^{2+}, \mathrm{Mn}^{2+} \mathrm{Hg}^{2+}, \mathrm{Ca}^{2+}, \mathrm{Mg}^{2+}, \mathrm{Sr}^{2+}, \mathrm{Ni}^{2+}$ and $\mathrm{Cd}^{2+}$ was added to $1 \mathrm{~mL}$ OMRTH-AgNps and from the different sets of experiments it was observed that OMRTHAgNps showed blue shift in surface plasmon resonance and maximum fluorescence quenching only in the presence of $\mathrm{Cd}[\mathrm{II}]$. Hence, to evaluate the minimum detectable limit of $\mathrm{Cd}[\mathrm{II}], 10-1000$ times dilution of $\mathrm{Cd}[\mathrm{II}]$ was done.

\section{Result and discussion}

\section{Formation mechanism of silver nanoparticles: UV-visible spectra and stability study}

The chemical reduction of silver ions by a highly reducing agent is usually very quick. In this study, no commonly known reducing agents were employed for the rapid formation of silver nanoparticles. Here, octamethoxy resorcin (Park et al. 2007) arene tetrahydrazide (OMRTH) has been used for the synthesis of silver nanoparticles, where OMRTH acted as reducing as well as capping agent. Octamethoxy resorcin (Park et al. 2007) arene tetrahydrazide (OMRTH) can passivate the surface of the silver nanoparticles and stabilize nanoparticles owing to the coordination of nitrogen atoms of the hydrazide $\left(-\mathrm{NH}-\mathrm{NH}_{2}\right)$ group with silver atoms at the surface of silver nanoparticles (Chen et al. 2007). It is therefore anticipated that silver nanoparticles are covered with a layer of OMRTH or by its oxidized product. The preparation of OMRTH-AgNps was carried out by a simple one-pot process and the color change observed was from colorless to yellow.

The as-prepared OMRTH-AgNps were primarily characterized by UV-visible spectroscopy, one of the most widely used techniques for the structural characterization of nanoparticles. According to Mie's theory (Mie 1908), for spherical nanoparticles, only a single surface plasmon resonance (SPR) band is expected, whereas two or more SPR bands are observed for anisotropic particles depending on the shape of the particles. There is also a well-established relationship between nanoparticle size and SPR band position, i.e., with an increase in size of particle, plasmon resonance band shifting to the red and vice versa (Leff et al. 1995). The synthesized OMRTH-AgNps showed a single surface plasmon band at $415 \mathrm{~nm}$ Fig. 1 and remained the same for more than 6 months (Figure 2 indicating the presence of highly stable and spherical silver nanoparticles (Sosa et al. 2003).

\section{Silver nanoparticles: TEM and particle size analyzer observations with their zeta potential values}

The size distribution of the fluorescent Ag nanoparticles was characterized by two techniques, transmission electron microscopy (TEM) and particle size analyzer (PSA). TEM is used to visualize the shape as well as to measure the diameter of nanoparticles. PSA provides information regarding the size of aggregates rather than the diameter of individual particles. PSA value was high because it is the average hydrodynamic diameter. The higher value of PSA is due to the light scattered by the core particle and the layers formed on the surface of the particles.TEM image of (OMRTH-AgNps) as shown in Fig. 3 depicts that the synthesized silver nanoparticles are more or less monodispersed with spherical or roughly spherical shape and have an average diameter of $5 \mathrm{~nm}$ with the majority of particles within the size range of 3-7 nm. Also, no aggregation or formation of large particles was observed by the TEM image. The particles are homogeneously monodispersed with most of the particles at $5.0 \mathrm{~nm}$, as

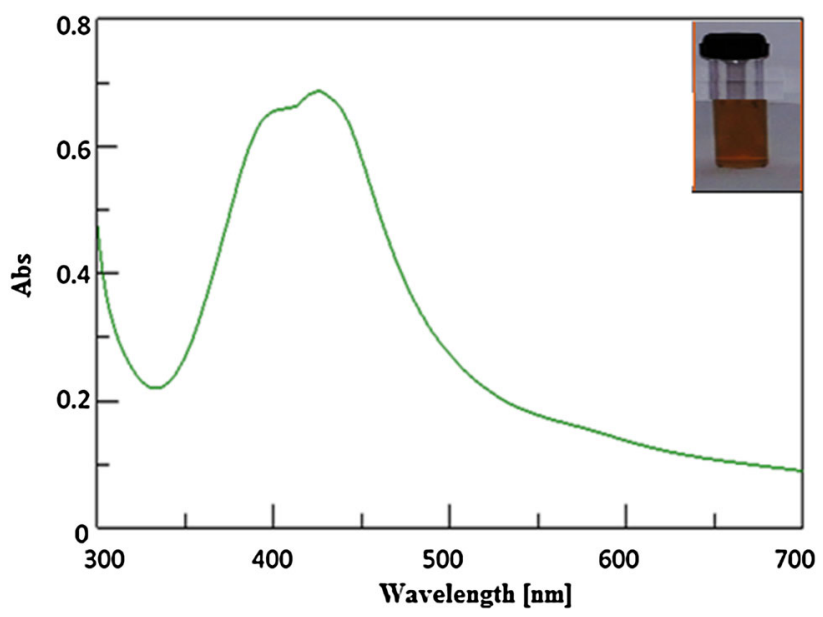

Fig. 1 UV-visible spectra of OMRTH-AgNps 


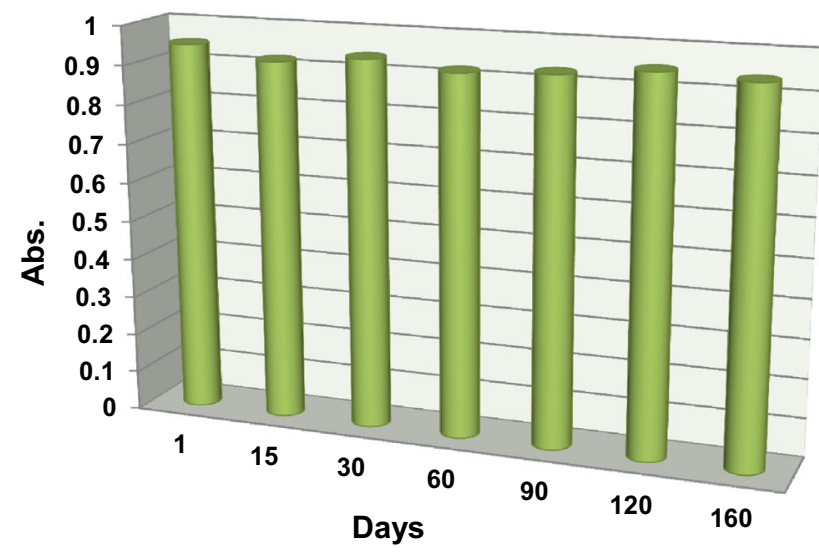

Fig. 2 Stability of OMRTH-AgNps with respect to time

evident from the image (Fig. 3c). Selected area electron diffraction study (SAED) showed the presence of the (111) plane for silver nanoparticles. Hence, from the electron diffraction pattern, it is clear that the particles are crystalline in nature. Electron diffraction analysis showed diffuse ring patterns and crystal spots, which indicated a randomly oriented, finely crystalline nanostructure, When the electron diffraction is carried out on a limited number of crystals, one observes only some spots of diffractiondistributed concentric circles. The ring patterns with plane distances are consistent with the plane families of pure face-centered cubic (fcc) silver structure. The clear lattice fringes in TEM images and the electron diffraction (ED) pattern with circular rings and planes show that the nanoparticles obtained are highly crystalline.

The size distribution of the silver nanoparticles was also measured by Malvern's particle size analyzer (PSA). As shown in the Fig. $4 \mathrm{a}$, the particles are homogeneously monodispersed with an average particle size in the range of 15-22 $\mathrm{nm}$. The statistical graph and size distribution vs intensity have been shown in Fig. 4b. The overall particle charge in a particular medium is denoted as their zeta potential value, which is responsible for deciding the fate of stability. Here, synthesized silver nanoparticles had a $12 \pm 4 \mathrm{MeV}$ zeta potential values, which is sufficient to keep the particles away from aggregation and to maintain the stability. Moreover, a positive value also suggests that hydrazide groups were successfully introduced on the surface of nanoparticles.

\section{Effect of pH on the relative UV-visible absorption and fluorescence intensity}

The $\mathrm{pH}$-dependent stability of OMRTH-AgNps was studied at different $\mathrm{pH}$ values from 4 to 7 by observing their absorption as well as emission spectrum. No considerable change in absorption spectra of nanoparticles was observed at different $\mathrm{pH}$ ranges from 4 to $7 \mathrm{Fig}$. 5 On the other hand, from the fluorescence emission spectra, it was concluded that the maximum relative fluorescence intensity of silver nanoparticles was $4.5 \mathrm{pH}$ and, hence, this $\mathrm{pH}$ was selected for further fluorescence-related studies Fig. 6

\section{Silver nanoparticles: metal ion and sensing study and quenching mechanism}

From the fluorescence spectra of silver nanoparticles, maximum emission was observed at $458 \mathrm{~nm}$ Fig. 7 To ensure the high selectivity of the sensing for metal ions, the interaction of silver nanoparticles with different metal ions such as $\mathrm{Zn}, \mathrm{Pb}, \mathrm{Co}, \mathrm{Cu}, \mathrm{Ba}, \mathrm{Cd}, \mathrm{Mn}, \mathrm{Hg}, \mathrm{Ca}, \mathrm{Mg}, \mathrm{Sr}$ and $\mathrm{Ni}$
Fig. 3 a TEM image of OMRTH-reduced AgNps, b particle size distribution graph and $\mathbf{c}$ electron diffraction pattern

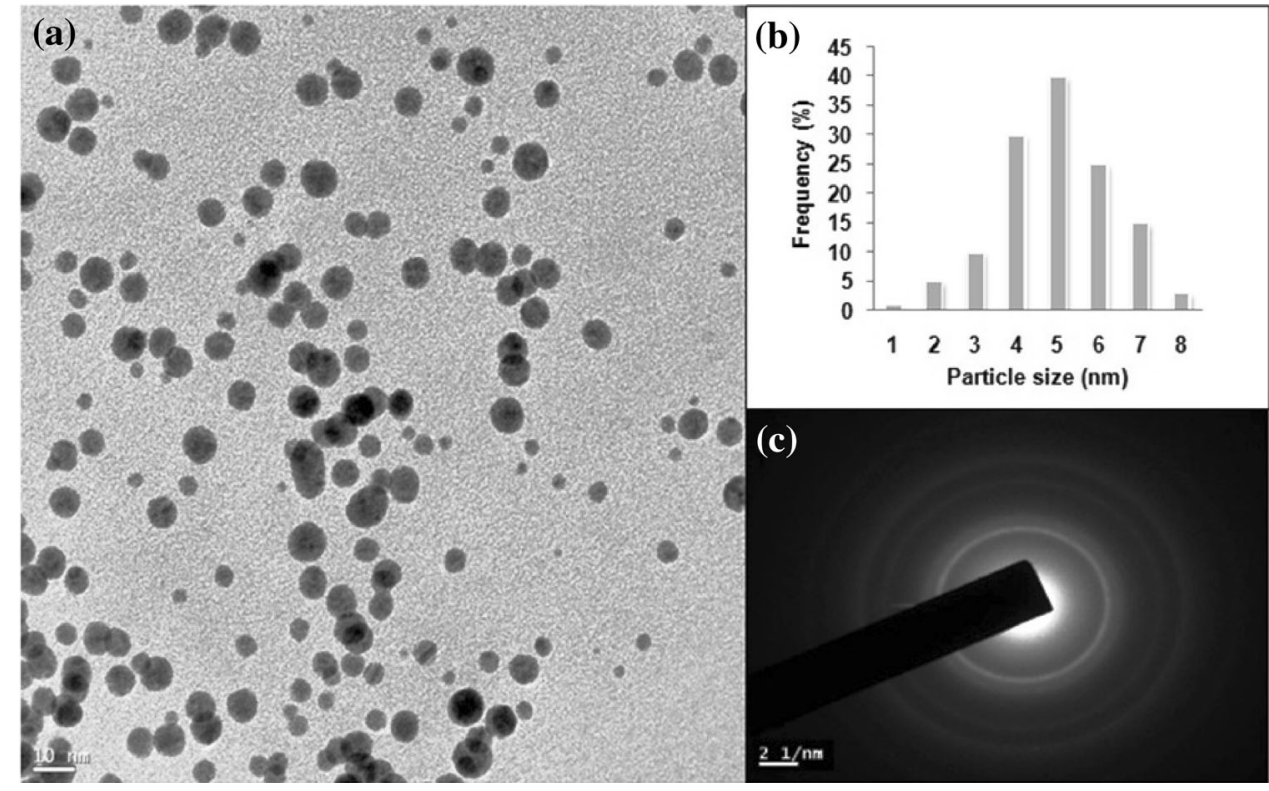


(a)
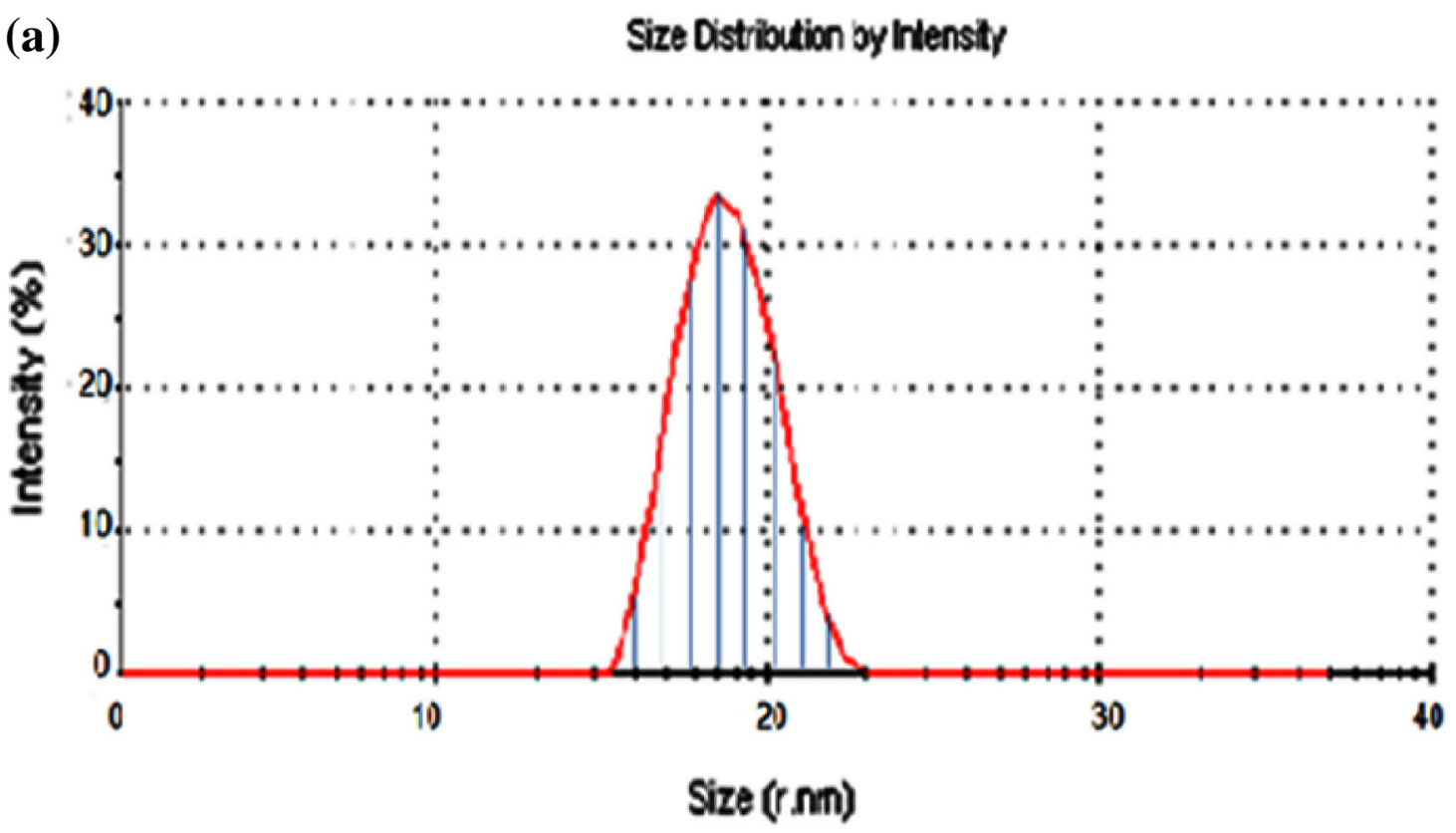

(b)

Zota Potental Distribuion

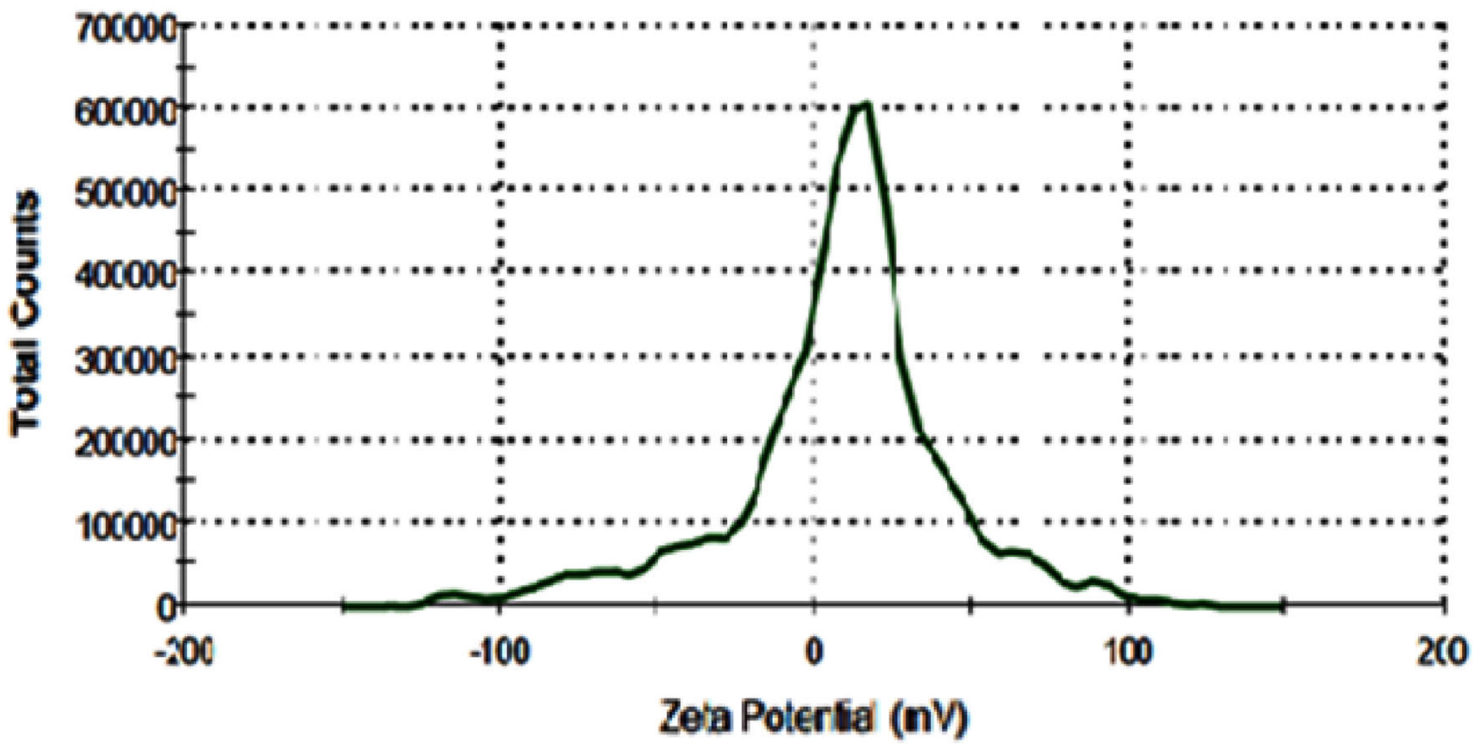

Fig. 4 a Size distribution of silver nanoparticles by particle size analyzer. b Zeta potential

has been studied under similar conditions. For fluorescence emission study, the concentration of metal ions initially taken was $10^{-8} \mathrm{M}$ and gradually increased to $10^{-6} \mathrm{M}$. It was observed that with an increase in the concentration of cadmium, the fluorescence emission was quenched rapidly up to $85 \%$ at a concentration of $10^{-6} \mathrm{M}$, while no considerable quenching effect was observed (Fig. 8) upon addition of other metal ions up to $10^{-6} \mathrm{M}$ concentration. The relative fluorescence quenching toward various common metal ions is presented in Fig. 9, which suggests that the synthesized silver nanoparticles are selective for cadmium only.

Several mechanisms have been proposed to explain the fluorescence quenching of nanoparticles, including inner filter effects, non-radiative recombination pathways and electron transfer process (Gattás-Asfura and Leblanc 2003). Quenching often proceeds via the formation of the complex at an excited state, i.e., an exciplex (collisional quenching), or by ground state complex formation (static quenching). 


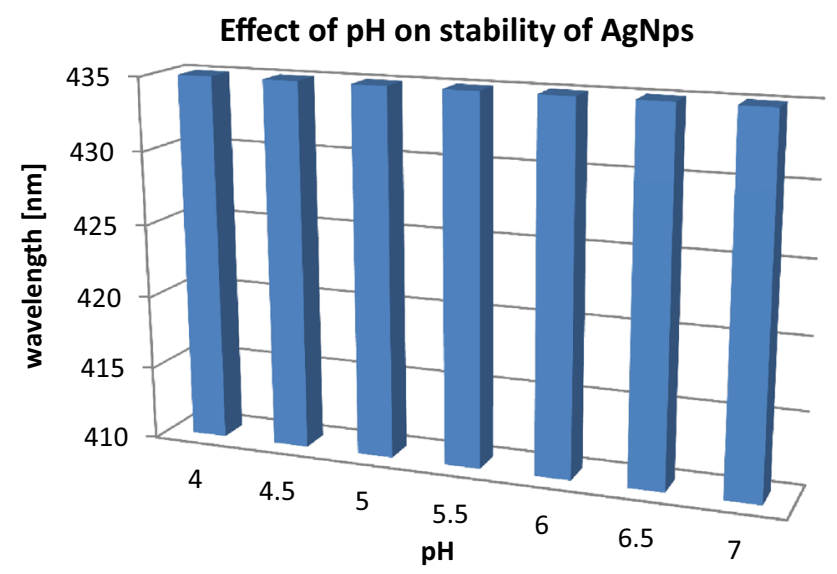

Fig. 5 Effect of $\mathrm{pH}(4-7)$ on the stability of OMRTH-AgNps

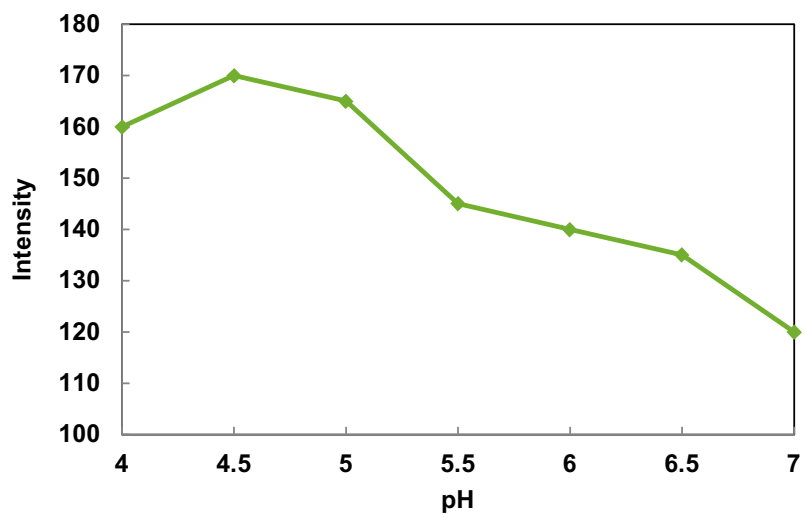

Fig. 6 Relative fluorescence intensity of OMRTH-AgNPs at different $\mathrm{pH}$ values

There is an excellent linear relationship of fluorescence quenching with concentration of cadmium within the range of $10^{-8} \mathrm{M}(10 \mathrm{nM})$ to $10^{-6} \mathrm{M}(1 \mu \mathrm{M})$. Figure 10 suggests that the quenching effect of synthesized silver nanoparticles by cadmium ions was in accordance with Stern-Volmer equation (Eq. 1):

$F_{0} / F=1+K_{\mathrm{sv}}[Q]$,

where $F_{0}$ and $F$ are the steady-state fluorescence intensities in the absence and presence of quencher, respectively, $K_{\mathrm{sv}}$ is the Stern-Volmer quenching constant which defines the quenching efficiency and $[Q]$ is the concentration of the quencher, i.e., concentration of $\mathrm{Cd}[\mathrm{II}]$.

The fluorescence data were analyzed by plotting $F_{0} /$ $F$ versus concentration of $\mathrm{Cd}$. The resulting Stern-Volmer plot between the fluorescence decreases with the concentration of $\mathrm{Cd}$ ion over the range of $10^{-8}$ to $10^{-6} \mathrm{M}$ as shown in Fig. 10 and exhibits a good linear relationship with a correlation coefficient of $R^{2}=0.9874$. Also, the absorption spectrum of OMRTH-AgNps varied after the addition of cadmium Fig. 11, indicating that static quenching was involved; for dynamic quenching, the



Fig. 7 Fluorescence spectra of OMRTH-AgNps

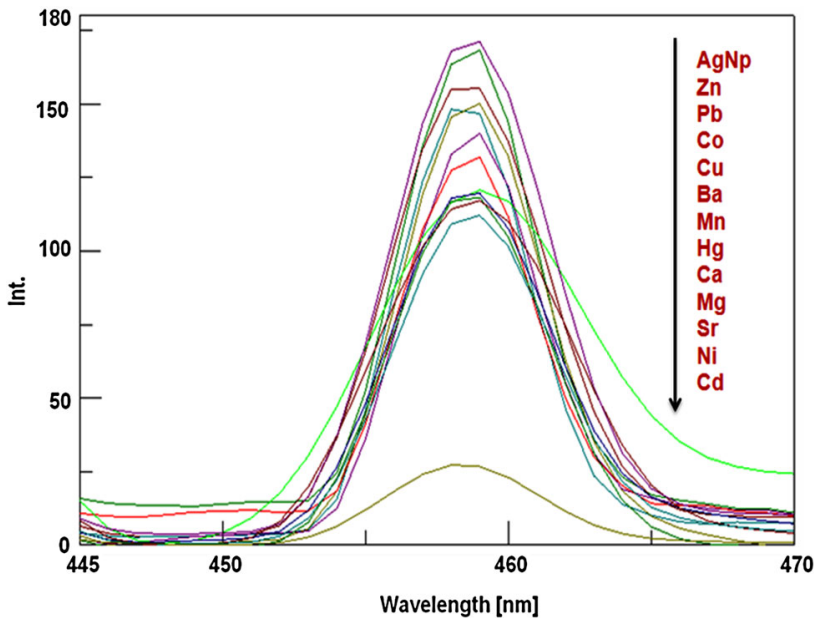

Fig. 8 Fluorescent spectra of OMRTH-AgNps interaction with different transition metal ions

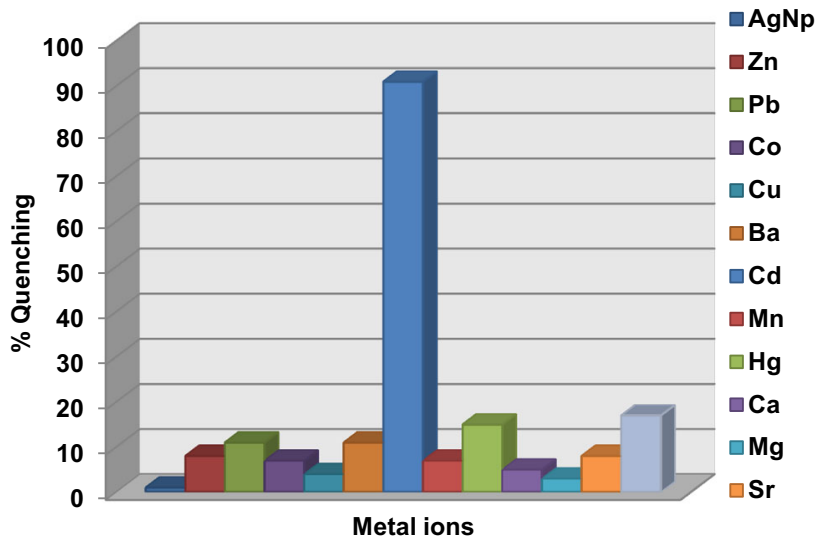

Fig. 9 Relative fluorescence quenching toward various common metal ions

excited-state fluorochrome molecule had no effect on the absorption spectrum (Kim et al. 2012; Yin et al. 2011). Functionalized silver nanoparticles were aggregated in 


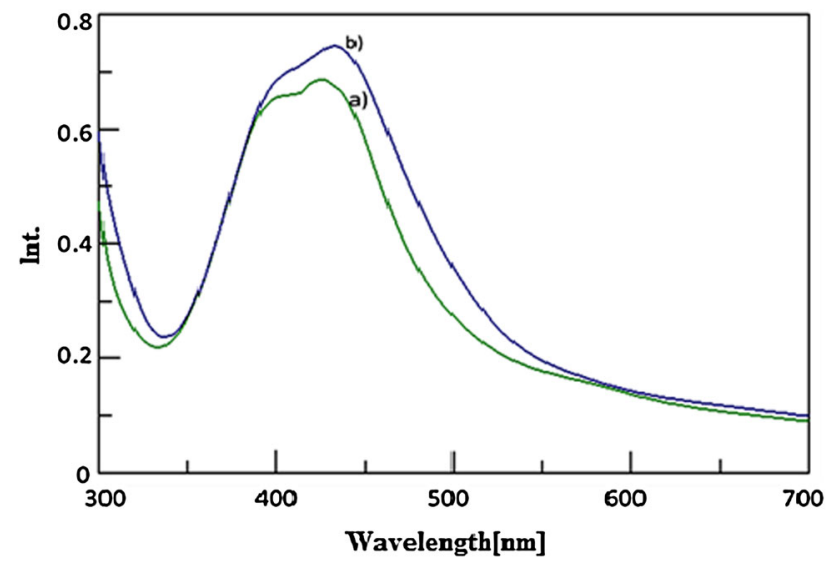

Fig. 10 SPR band of $a$ OMRTH-AgNps in the presence of Cd[II] ions. $b$ OMRTH-AgNps without metal ions

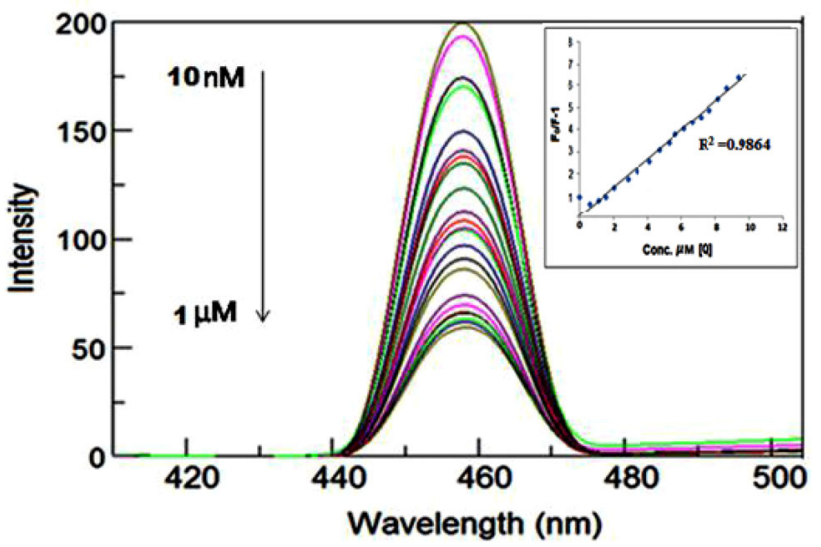

Fig. 11 Fluorescence response of OMRTH-AuNps on addition of $\mathrm{Cd}[\mathrm{II}](10 \mathrm{nM}$ to $1 \mu \mathrm{M})$. The inset shows a Stern-Volmer plot of intensity versus concentration of $\mathrm{Cd}[\mathrm{II}]$

solution in the presence of divalent metal ions by an iontemplated chelation process, which induced an easily measurable change in the absorption spectrum of the particles. The aggregation also enhanced the hyper-Rayleigh scattering (HRS) response from the nanoparticle solutions, providing an inherently more sensitive method of detection (Kim et al. 2012).

AgNps detects the other metal ions, but retains a marked selectivity with cadmium ions (Meallet-Renault et al. 2006; 2006) It is reasonable to believe that the size of $\mathrm{Cd} 21$ can fit better with the ring than other transition metal ions tested. Therefore, the modifiers of OMRTH-Ag NPs show a good sequestration of $\mathrm{Cd}^{2+}$ which results in $\mathrm{Cd}^{2+}$ inducing the aggregation of OMRTH-Ag NP (Chowdhury et al. 2011).The fluorescence quenching of OMRTH-capped AgNPs in the presence of $\mathrm{Cd}^{2+}$ ion was attributed to nanoparticle aggregation induced by the complexation between OMRTH and $\mathrm{Cd}^{2+}$ ion. Upon interaction with different bivalent and trivalent metal ions, for $\mathrm{Cu}^{2+}$ ion, whereas the fluorescence intensity of the AgNps fluorescence intensity shows a substantial decrease, OMRTHcapped AgNPs is nearly unaffected by metal ions other than $\mathrm{Cd}^{2+}$. That complexation between OMRTH-AgNps and $\mathrm{Cd}^{2+}$ ion induced aggregation and fluorescence quenching of OMRTH-capped AgNPs was further confirmed by a competition test.

\section{Application}

Herein, we report the selective detection of $\mathrm{Cd}[\mathrm{II}]$ ions in Sabarmati River (Ahmedabad) and tap water from the university area which was found to be 28.50 and $41.75 \mathrm{nM}$, respectively. To further confirm the results, the standard addition method was adopted. To $0.9 \mathrm{~mL}$ OMRTH-AgNps solution, $0.05 \mathrm{~mL}$ of standard $\mathrm{Cd}[\mathrm{II}]$ ions of different strengths $(200,300,500$ and $700 \mathrm{nM})$ was spiked, followed by the addition of $0.05 \mathrm{~mL}$ sample solution. Since decrease in relative fluorescence intensity is linear with successive

Table 1 Determination of Cd(II) ions in different water samples

\begin{tabular}{|c|c|c|c|c|c|c|}
\hline Samples & $\begin{array}{l}\text { Reference } \\
\text { concentration } \\
(\mathrm{nM})\end{array}$ & $\begin{array}{l}\text { Quenching } \\
\left(I / I_{0}\right)-1 \\
\text { Istd }\end{array}$ & $\begin{array}{l}\text { Quenching } \\
\left(I / I_{0}\right)-1 \\
\text { Iws }\end{array}$ & $\begin{array}{l}\text { Concentration of } \mathrm{Cd}(\mathrm{II}) \\
(\mathrm{nM}) \text { obtain from Fig. } 10\end{array}$ & $\begin{array}{l}\text { Concentration of } \mathrm{Cd}(\mathrm{II}) \\
(\mathrm{nM}) \text { in the sample } \\
\text { solution }\end{array}$ & $\begin{array}{l}\text { Average } \\
\text { concentration of } \\
\text { Cd(II) }(n M)\end{array}$ \\
\hline \multirow{4}{*}{$\begin{array}{l}\text { Tap water } \\
\text { (University area, } \\
\text { Ahmedabad) }\end{array}$} & 200 & 3.75 & 3.67 & 215 & 15 & \multirow[t]{4}{*}{28.50} \\
\hline & 300 & 2.45 & 2.31 & 327 & 27 & \\
\hline & 500 & 0.72 & 0.78 & 534 & 34 & \\
\hline & 700 & 0.26 & 0.20 & 738 & 38 & \\
\hline \multirow{4}{*}{$\begin{array}{l}\text { Sabarmati River } \\
\text { (Ahmedabad) }\end{array}$} & 200 & 3.75 & 3.50 & 221 & 21 & \multirow[t]{4}{*}{41.75} \\
\hline & 300 & 2.45 & 2.12 & 338 & 38 & \\
\hline & 500 & 0.72 & 0.64 & 550 & 50 & \\
\hline & 700 & 0.26 & 0.17 & 758 & 58 & \\
\hline
\end{tabular}

Intensity Istd: \% Fluorescence intensity decrease after the standard $\mathrm{Cd}(\mathrm{II})$ ions solution only

Intensity Iws: \% Fluorescence intensity decreases after the standard $\mathrm{Cd}(\mathrm{II})$ ions solution and water samples both

I maximum intensity after the addition of $\mathrm{Cd}(\mathrm{II}) 1000 \mathrm{nM}, I_{0}$ absence of Cd(II) ion (only OMRTH-AgNps) 
addition of $\mu \mathrm{M}$ concentration of $\mathrm{Cd}[\mathrm{II}]$ ions, the fluorescence intensity of the resulting solution of four different sets was measured and the graph plotted between the percent intensity decrease $\left(I / I_{0}\right)-1$ and concentration of $\mathrm{Cd}[\mathrm{II}]$ ions, where $(I)$ and $\left(I_{0}\right)$ are the fluorescence intensity of OMRTH-AgNps in the absence of $\mathrm{Cd}[\mathrm{II}]$ ions and presence of $\mathrm{Cd}[\mathrm{II}]$ ions (Table 1).

\section{Conclusion}

In conclusion, OMRTH-functionalized fluorescent silver nanoparticles were successfully synthesized through a simple one-pot method. It shows that a noble and efficient nanoconjugation has been explored which open ups a new way to prepare functionalized fluorescent probes. Further, we have demonstrated the application of OMRTH-AgNps as a sensitive and selective probe for the detection of $\mathrm{Cd}[\mathrm{II}]$. Cadmium ions can be detected by a "turn off" fluorescence mechanism at minimum concentration of about $10^{-8} \mathrm{M}$ and, hence, these newly synthesized OMRTH-AgNps-based silver nanoparticles will act as a very good cadmium probe and can hold a very good future in biolabeling, biosensing and in many more fields. We believe that these easily synthesized and stabilized silver nanoparticles (OMRTH-AgNps) may find application in various areas of analytical and bioanalytical chemistry as well as be an excellent platform for the rapid detection of Cd[II]. The OMRTH-AgNps can also be explored for their use in the detection of $\mathrm{Cd}[\mathrm{II}]$ ions in environmental and biological samples..

Acknowledgments The authors gratefully acknowledge the financial assistance provided by GUJCOST, Gandhinagar, and University Grant Commission (UGC), New Delhi. The authors also acknowledge CSMCRI (Bhavanagar), GFSU (Gandhinagar) and CDRI (Lucknow) for providing instrumental facilities, and INFLIBNET, Ahmedabad, for e-journals. We are also thankful to the Department of Microbiology (Gujarat University) for help in antimicrobial studies.

Open Access This article is distributed under the terms of the Creative Commons Attribution 4.0 International License (http://creativecommons.org/licenses/by/4.0/), which permits unrestricted use, distribution, and reproduction in any medium, provided you give appropriate credit to the original author(s) and the source, provide a link to the Creative Commons license, and indicate if changes were made.

\section{References}

Alexander Wei BK, Pusztay Stephen V, Tripp Steven L, Balasubramanian R, Kim B, Tripp Steven L, Wang Xuejun (2001) Resorcinarene-encapsulated nanoparticles: building blocks for self-assembled nanostructures. J Incl Phenom Macrocycl Chem 41:83-86
Balasubramanian R, Xu J, Kim B, Sadtler B, Wei A (2001) Extraction and dispersion of large gold nanoparticles in nonpolar solvents. J Dispers Sci Technol 22(5):485-489

Balasubramanian R, Kim B, Tripp SL, Wang X, Lieberman M, Wei A (2002a) Dispersion and Stability Studies of ResorcinareneEncapsulated Gold Nanoparticles. Langmuir ACS J Surfaces Colloids 18:3676-3681

Balasubramanian R, Kim B, Tripp SL, Wang X, Lieberman M, Wei A (2002b) Dispersion and stability studies of resorcinarene-encapsulated gold nanoparticles. Langmuir 18(9):3676-3681

Bao Y, Zhong C, Vu DM, Temirov JP, Dyer RB, Martinez JS (2007) Nanoparticle-free synthesis of fluorescent gold nanoclusters at physiological temperature. J Phys Chem C 111(33): 12194-12198

Ben-Ishay ML, Gedanken A (2007) Difference in the Bonding Scheme of Calix (6) arene and p-Sulfonic Calix (6) arene to Nanoparticles of $\mathrm{Fe} 2 \mathrm{O} 3$ and $\mathrm{Fe} 3 \mathrm{O} 4$. Langmuir ACS J Surfaces Colloids 23(10):5238-5242

Bhatt KD, Vyas DJ, Makwana BA, Darjee SM, Jain VK (2014) Highly stable water dispersible calix [4] pyrrole octa-hydrazide protected gold nanoparticles as colorimetric and fluorometric chemosensors for selective signaling of Co (II) ions. Spectrochim Acta Part A Mol Biomol Spectrosc 121:94-100

Bönnemann H, Brijoux W, Brinkmann R, Fretzen R, Joussen T, Köppler R, Korall B, Neiteler P, Richter J (1994) Preparation, characterization, and application of fine metal particles and metal colloids using hydrotriorganoborates. J Mol Catal 86(1-3):129-177

Burda C, Chen X, Narayanan R, El-Sayed MA (2005) Chemistry and properties of nanocrystals of different shapes. Chem RevColumb 105(4):1025-1102

Caruso RA, Ashokkumar M, Grieser F (2000) Sonochemical formation of colloidal platinum. Colloids Surf A Physicochem Eng Asp 169(1-3):219-225

Chen S (2001) Electrochemical Studies of Langmuir-Blodgett thin films of electroactive nanoparticles. Langmuir 17(21):6664-6668

Chen M, Feng Y-G, Wang X, Li T-C, Zhang J-Y, Qian D-J (2007) Silver nanoparticles capped by oleylamine: formation, growth, and self-organization. Langmuir 23(10):5296-5304. doi:10. 1021/la700553d

Chowdhury S, Bhethanabotla VR, Sen R (2011) Quenching of Fluorescence from CdSe/ZnS Nanocrystal QDs Near Copper Nanoparticles in Aqueous Solution. Plasmonics 6(4):735-740

Chung YM, Rhee HK (2004) Dendrimer-templated Ag 瑖 Pd bimetallic nanoparticles. J Colloid Interface Sci 271(1):131-135

Curiel D, Cowley A, Beer PD (2005) Indolocarbazoles: a new family of anion sensors. Chem Commun 2:236-238

Dobson S (1992) Cadmium: environmental aspects. World Health Organization, Geneva

El-Sayed MA (2004) Small is different: shape-, size-, and composition-dependent properties of some colloidal semiconductor nanocrystals. Acc of Chem Res 37(5):326-333

Fujimoto T, Terauchi S, Umehara H, Kojima I, Henderson W (2001) Sonochemical preparation of single-dispersion metal nanoparticles from metal salts. Chem Mater 13(3):1057-1060

Gattás-Asfura KM, Leblanc RM (2003) Peptide-coated CdS quantum dots for the optical detection of copper (II) and silver (I). Chem Commun 21:2684-2685

Henglein A (1993) Physicochemical properties of small metal particles in solution:" microelectrode" reactions, chemisorption, composite metal particles, and the atom-to-metal transition. J Phys Chem 97(21):5457-5471

Hodes G (2007) When small is different: some recent advances in concepts and applications of nanoscale phenomena. Adv Mater 19(5):639-655 
Huang CC, Yang Z, Lee KH, Chang HT (2007) Synthesis of highly fluorescent gold nanoparticles for sensing mercury (II). Angew Chem 119(36):6948-6952

Huang CC, Chiang CK, Lin ZH, Lee KH, Chang HT (2008) Bioconjugated gold nanodots and nanoparticles for protein assays based on photoluminescence quenching. Anal Chem 80(5):1497-1504

Kevin B, Stavens SVP, Zou Shouzhong, Andres Ronald P, Wei Alexander (1999) Encapsulation of neutral gold nanoclusters by resorcinarenes. Langmuir ACS J Surf Colloids 15(24):83388339

Kim B, Tripp SL, Wei A (2001) Self-organization of large gold nanoparticle arrays. J Am Chem Soc 123(32):7955-7956

Kim YG, Oh SK, Crooks RM (2004) Preparation and characterization of 1-2 nm dendrimer-encapsulated gold nanoparticles having very narrow size distributions. Chem Mater 16(1):167-172

Kim B, Balasubramanian R, Pérez-Segarraa W, Wei A, Decker B, Mattay J (2005) Self-assembly of resorcinarene-stabilized gold nanoparticles: influence of the macrocyclic headgroup. Supramol Chem 17(1-2):173-180

Kim HN, Ren WX, Kim JS, Yoon J (2012) Fluorescent and colorimetric sensors for detection of lead, cadmium, and mercury ions. Chem Soc Rev 41(8):3210-3244

Klein G, Kaufmann D, Schürch S, Reymond JL (2001) A fluorescent metal sensor based on macrocyclic chelation Electronic supplementary information (ESI) available: electrospray MS data and photographs of solutions of ligand $3 \mathrm{c}$ in the absence and presence of $\mathrm{Cu} 2+$. See http://www.rsc.org/suppdata/cc/b1/ b100535i. Chemical Communications (6):561-562

Klingelhöfer S, Heitz W, Greiner A, Oestreich S, Förster S, Antonietti M (1997) Preparation of palladium colloids in block copolymer micelles and their use for the catalysis of the heck reaction. J Am Chem Soc 119(42):10116-10120

Leff DV, Ohara PC, Heath JR, Gelbart WM (1995) Thermodynamic control of gold nanocrystal size: experiment and theory. J Phys Chem 99(18):7036-7041

Luo H-Y, Jiang J-H, Zhang X-B, Li C-Y, Shen G-L, Yu R-Q (2007) Synthesis of porphyrin-appended terpyridine as a chemosensor for cadmium based on fluorescent enhancement. Talanta 72(2):575-581

Macdonald IDG, Smith WE (1996) Orientation of cytochrome c adsorbed on a citrate-reduced silver colloid surface. Langmuir 12(3):706-713

Makwana BA, Vyas DJ, Bhatt KD, Jain VK, Agrawal YK (2014) Highly stable antibacterial silver nanoparticles as selective fluorescent sensor for Fe 3+ ions. Spectrochim Acta A Mol Biomol Spectrosc 134:73-80

Makwana BA, Vyas DJ, Bhatt KD, Jain VK, Agrawal YK (2015) Highly stable antibacterial silver nanoparticles as selective fluorescent sensor for $\mathrm{Fe} 3+$ ions. Spectrochim Acta A Mol Biomol Spectrosc 134:73-80. doi:10.1016/j.saa.2014.05.044

Meallet-Renault R, Herault A, Vachon JJ, Pansu RB, AmigoniGerbier S, Larpent C (2006) Fluorescent nanoparticles as selective $\mathrm{Cu}(\mathrm{II})$ sensors. Photochem Photobiol Sci Off J Eur Photochem Assoc Eur Soc Photobiol 5(3):300-310. doi:10.1039/ b513215k

Méallet-Renault R, Hérault A, Vachon J-J, Pansu RB, AmigoniGerbier S, Larpent C (2006) Fluorescent nanoparticles as selective Cu (II) sensors. Photochem Photobiol Sci 5(3):300-310

Mie G (1908) A contribution to the optics of turbid media, especially colloidal metallic suspensions. Ann Phys (Leipzig) 25(3): $377-445$

Misra TK, Chen TS, Liu CY (2006) Phase transfer of gold nanoparticles from aqueous to organic solution containing resorcinarene. J Colloid Interface Science 297:584-588
Mizukami S, Nagano T, Urano Y, Odani A, Kikuchi K (2002) A fluorescent anion sensor that works in neutral aqueous solution for bioanalytical application. J Am Chem Soc 124(15):3920-3925

Moore D, Watson GW, Gunnlaugsson T, Matthews SE (2008) Selective formation of the rctt chair stereoisomers of octa-Oalkyl resorcin[4]arenes using Brønsted acid catalysis. New J Chem 32(6):994. doi:10.1039/b714735j

Murphy CJ, Gole AM, Stone JW, Sisco PN, Alkilany AM, Goldsmith EC, Baxter SC (2008) Gold nanoparticles in biology: beyond toxicity to cellular imaging. Acc Chem Res 41(12):1721-1730

Park J, Joo J, Kwon SG, Jang Y, Hyeon T (2007) Synthesis of monodisperse spherical nanocrystals. Angew Chem Int Edition 46(25):4630-4660

Petty JT, Zheng J, Nicholas V, Dickson RM (2004) DNA-templated Ag nanocluster formation. J Am Chem Soc 126(16):5207-5212

Puntes VF, Zanchet D, Erdonmez CK, Alivisatos AP (2002) Synthesis of hcp-Co nanodisks. J Am Chem Soc 124(43):12874-12880

Rahim EH, Kamounah FS, Frederiksen J, Christensen JB (2001) Heck reactions catalyzed by PAMAM-dendrimer encapsulated Pd (0) nanoparticles. Nano Lett 1(9):499-501

Raveendran P, Fu J, Wallen SL (2003) Completely "green" synthesis and stabilization of metal nanoparticles. J Am Chem Soc 125(46):13940-13941

Reetz MT, Helbig W (1994) Size-selective synthesis of nanostructured transition metal clusters. J Am Chem Soc 116(16):7401-7402

Resendiz MJ, Noveron JC, Disteldorf H, Fischer S, Stang PJ (2004) A Self-assembled supramolecular optical sensor for Ni (II), Cd (II), and $\mathrm{Cr}(\mathrm{III})$. Org Lett 6(5):651-653

Ritchie CM, Johnsen KR, Kiser JR, Antoku Y, Dickson RM, Petty JT (2007) Ag nanocluster formation using a cytosine oligonucleotide template. J Phys Chem C 111(1):175-181

Salorinne K, Lopez-Acevedo O, Nauha E, Häkkinen H, Nissinen M (2012) Solvent driven formation of silver embedded resorcinarene nanorods. CrystEngComm 14(2):347-350

Sau TK, Murphy CJ (2004) Room temperature, high-yield synthesis of multiple shapes of gold nanoparticles in aqueous solution. J Am Chem Soc 126(28):8648-8649

Shang L, Dong S (2008) Facile preparation of water-soluble fluorescent silver nanoclusters using a polyelectrolyte template. Chem Commun 9:1088-1090

Shen Z, Duan H, Frey H (2007) Water-soluble fluorescent Ag nanoclusters obtained from multiarm star poly (acrylic acid) as "molecular hydrogel" templates. Adv Mater 19(3):349-352

Sosa IO, Noguez C, Barrera RG (2003) Optical properties of metal nanoparticles with arbitrary shapes. J Phys Chem B 107(26): 6269-6275

Stavens KB, Pusztay SV, Zou S, Andres RP, Wei A (1999) Encapsulation of neutral gold nanoclusters by resorcinarenes. Langmuir 15(24):8337-8339

Sun Y, Yao Y, Yan CG, Han Y, Shen M (2010) Selective decoration of metal nanoparticles inside or outside of organic microstructures via self-assembly of resorcinarene. ACS Nano 4(4):2129-2141

Thomas KG, Barazzouk S, Ipe BI, Joseph STS, Kamat PV (2004) Uniaxial plasmon coupling through longitudinal self-assembly of gold nanorods. J Phys Chem B 108(35):13066-13068

Triulzi RC, Micic M, Giordani S, Serry M, Chiou WA, Leblanc RM (2006) Immunoasssay based on the antibody-conjugated PAMAM-dendrimer-gold quantum dot complex. Chem Commun 48:5068-5070

Turkevich J, Kim G (1970) Palladium: preparation and catalytic properties of particles of uniform size. Science 169(3948):873-879

Velanki S, Kelly S, Thundat T, Blake DA, Ji H-F (2007) Detection of $\mathrm{Cd}(\mathrm{II})$ using antibody-modified microcantilever sensors. Ultramicroscopy 107(12):1123-1128. doi:10.1016/j.ultramic.2007.01. 011 
Wang A-J, Guo H, Zhang M, Zhou D-L, Wang R-Z, Feng J-J (2013) Sensitive and selective colorimetric detection of cadmium (II) using gold nanoparticles modified with 4-amino-3-hydrazino5-mercapto-1, 2, 4-triazole. Microchim Acta 180(11-12): $1051-1057$

Wei A, Kim B, Pusztay SV, Tripp SL, Balasubramanian R (2001) Resorcinarene-encapsulated nanoparticles: building blocks for self-assembled nanostructures. J Incl Phenom Macrocycl Chem 41(1):83-86

Xu H, Suslick KS (2010) Water-Soluble Fluorescent Silver Nanoclusters. Adv Mater 22(10):1078-1082

Yao Y, Sun Y, Han Y, Yan C (2010) Preparation of resorcinarenefunctionalized gold nanoparticles and their catalytic activities for reduction of aromatic nitro compounds. Chin J Chem 28:705-712
Yin J, Wu T, Song J, Zhang Q, Liu S, Xu R, Duan H (2011) SERSactive nanoparticles for sensitive and selective detection of cadmium ion $(\mathrm{Cd} 2+)$. Chem Mater 23(21):4756-4764

Yu J, Patel SA, Dickson RM (2007) In vitro and intracellular production of peptide-encapsulated fluorescent silver nanoclusters. Angew Chem 119(12):2074-2076

Zhang M, Liu Y-Q, Ye B-C (2012) Colorimetric assay for parallel detection of $\mathrm{Cd} 2+$, Ni $2+$ and $\mathrm{Co} 2+$ using peptide-modified gold nanoparticles. Analyst 137(3):601-607

Zheng J, Dickson RM (2002) Individual water-soluble dendrimerencapsulated silver nanodot fluorescence. J Am Chem Soc 124(47):13982-13983

Zheng J, Nicovich PR, Dickson RM (2007) Highly fluorescent noble metal quantum dots. Annu Rev Phys Chem 58:409 